\title{
A New Route for Preparing CdS thin Films by Chemical Bath Deposition Using EDTA as Ligand
}

\author{
A. V. Feitosa ${ }^{\ddagger}$, M. A. R. Miranda ${ }^{\dagger}$, J. M. Sasaki ${ }^{\dagger}$, and M. A. Araújo-Silva ${ }^{\ddagger}$, \\ ${ }^{\ddagger}$ Lab. de Optoeletroquímica e Lab. de Filmes Finos, Departamento de Física, \\ Universidade Federal do Ceará, Centro de Ciências, Campus do Pici, Caixa Postal 6030, 60455-760 Fortaleza, Ceará, Brazil \\ ${ }^{\dagger}$ Lab. de Raios X, Departamento de Física, Universidade Federal do Ceará, Centro de Ciências, \\ Campus do Pici, Caixa Postal 6030, 60455-760 Fortaleza, Ceará, Brazil
}

Received on 31 March, 2003

\begin{abstract}
Progress is reported towards the development of a new route to obtain cadmium sulfide (CdS) thin films by using ethylene-diamine-tetra-acetic acid (EDTA) ligand on the chemical bath deposition (CBD) method. Different chemical baths are used to study changes in the structures of the CdS films for different EDTA concentrations. $\mathrm{X}$-ray diffraction (XRD) is used to prove the structural characterization of the samples, and to obtain the grain size with the Scherrer's equation. The $\mathrm{pH}$ variations during the growth also affect the structural film quality, and it was verified by using ammonia chloride as an auxiliar-buffer plus Triton-X100.
\end{abstract}

\section{Introduction}

In recent years, polycrystalline $\mathrm{CdS}$ thin films have received intensive attention due their very important role on the photovoltaic technology and optoelectronic devices. It has been used as a partner of several types of thin film solar cells, such as, $\mathrm{Cu}_{2} \mathrm{~S}, \mathrm{CuInSe} \mathrm{I}_{2}$, and CdTe. Specifically, CdTe/CdS heterojunction solar cells with efficiency of about $16 \%$ have been reported [1]. CdS thin film has been obtained by several methods, such as, electrodeposition, vacuum evaporation, screen printing, photochemical deposition, CBD, spray pyrolysis, and sputtering. CdS thin film manufacture technology has been the subject of several reviews [2 -4], where more details about it can be seen.

Particularly, the CBD technique is an easy low-cost process, and useful for large-area industrial applications, reason for which it has been very used in the current days. CBD is a process to achieve high quality films, which are obtained by adjusting the $\mathrm{pH}$, temperature and reagent concentrations.

Normally, for obtaining CdS thin films by CBD in aqueous solution a cadmium salt is used as the $\mathrm{Cd}$ ion source, thiourea as the sulfur source, a base to adjust the $\mathrm{pH}$ of solution, and a ligand to control the precipitation of chalcogenides and hydroxides. As far as we know, CdS thin films have been mainly obtained through CBD with ammonia and/or ethylenediamine (Lewis base) ligand [5 - 8]. Despite the advances in the processes of achieve CdS thin films many issues are opened, and new routes are welcome.

EDTA is an amino-derived organic-compound known to be a strong hexdentate chelanting agent. It forms a complex with metal ions and dissociates reversibly at a low rate. Lade and Lokhande [9] have used EDTA in the electro deposition of CdS thin films from non-aqueous bath. Furthermore, EDTA has been used in several process involving CdS col- loid [10] or cadmium particles [11, 12]. EDTA affects the adsortion and desortion processes of cadmium in red soil (ferrisoils) [13], and also, it affects the growth of CdS crystalline thin films by photochemical deposition [14].

In this work, we show a new route to the deposition of CdS thin films using CBD technique with EDTA ligand. Different concentrations of EDTA are proved to estimate the structural quality of the $\mathrm{CdS}$ thin films. Furthermore, the variation of $\mathrm{pH}$ during the growth is important in the structural film quality, and was observed experimentally by using ammonia chloride as an auxiliar-buffer. Triton-X100 (TX100) is a non-ionic surfactant that is widely employed in industry as a detergent, solubilizer, and emulsifier. In this work, it was employed with intention of improve the CdS film quality. The CdS thin films were characterized by XRD.

\section{Experimental}

CdS thin films were microstructurally characterized by $\mathrm{XRD}$, at room temperature, using a thin-film setup (PHILIPS, model XPERT-PRO) with $\mathrm{CuK} \alpha$ radiation operated at $40 \mathrm{kV}$ and $40 \mathrm{~mA}$. The grain sizes of polycrystalline film were inferred from experimental XRD using BraggBretano geometry setup by using the Scherrer's equation [15].

$\mathrm{CdS}$ thin films were deposited using CBD technique on glass commercial slide plates degreased and cleaned thoroughly by ultrasonic using a standard procedure. The films were kept at $80{ }^{\circ} \mathrm{C}\left( \pm 1{ }^{\circ} \mathrm{C}\right)$ during the growth. The growth time for each bath was ca. 55 minutes under continuous stirring. Three different aqueous alkaline solution with distilled and deionized water, and analytical-grade reagents were used. The EDTA concentration has changed from 0.6 
$\mathrm{x} 10^{-4} \mathrm{M}$ to $3.0 \times 10^{-4} \mathrm{M}$, with step of $0.3 \times 10^{-4} \mathrm{M}$, called of $\mathrm{C} 1$ to $\mathrm{C} 9$, respectively. In the group one, the solution containing cadmium sulfide $\left(\mathrm{CdSO}_{4}\right)(\mathrm{Cd}$ ion source) $0.003 \mathrm{M}$, thiourea (sulfur source) $0.06 \mathrm{M}$, ammonia (base and ligand) 2.3 M, and EDTA with four different concentrations, C1, $\mathrm{C} 3, \mathrm{C} 5$, and $\mathrm{C} 7$. In the group two the solution differs from the one by the addition of ammonia chloride $\left(\mathrm{NH}_{4} \mathrm{Cl}\right)$, that forms a buffer-solution with ammonia to keep the $\mathrm{pH}=11$, and EDTA with four different concentrations, C2, C4, C6, C8. In the group three, the solution differs from the solution two by the addition of TX100 at the solution buffer.

\section{Results and discussion}

One of the parameter that acts on the film quality is the relative concentration of chemical species present in the solution. The variation of the EDTA concentration has been used to obtain a qualitative influence of the ligand and the buffer solution on the formation of $\mathrm{CdS}$ film. Initially, $\mathrm{Cd}^{2+}$ ion co-ordinates with EDTA ligand to form Cd[EDTA $]^{2-}$ complex, that avoids the precipitation of undesirable material, as the cadmium hydroxide $\left[\mathrm{Cd}(\mathrm{OH})_{2}\right]$. In the next step, the complex will be broken with the addition of $\mathrm{S}^{2-}$ ion, forming $\mathrm{CdS}$. The $\mathrm{CdS}$ precipitation can take place either with the formation of colloids in the bulk of the solution (homogeneous reaction), or with the formation of a continuous film at the surface of the substrate (heterogeneous reaction) [7].

The obtained films were optically transparent, adherent, homogeneous and orange in color. X-ray patterns of samples of second solution group (with buffer solution, but without TX100) are shown in the Fig. 1. EDTA concentration of $\mathrm{C} 2=0.9 \times 10^{-4} \mathrm{M}, \mathrm{C} 4=1.5 \times 10^{-4} \mathrm{M}, \mathrm{C} 6=2.1 \times 10^{-4} \mathrm{M}$, and $\mathrm{C} 8=2.7 \times 10^{-4} \mathrm{M}$, were used and assigned to Fig. 1(a), (b), (c), and (d), respectively. The diffractogram show three peaks more intense, corresponding to the planes (111), (220) and (311), respectively, of the cubic phase of CdS film.

The grain size $\left(L_{c}=k \lambda \beta \cos \theta\right)$ for all samples were calculated by means of Scherrer's equation [15], where $k$ is related to the shape of the polycrystals, $\lambda$ is the $\mathrm{x}$-ray wavelength, $\beta$ is the full-width at half maximum (FWHM) of the respective diffraction peak and $\theta$ is the Bragg angle. According to the SEM images (not shown) of the CdS polycrystals, was choice $k=1$ for accounting the near spherical shape of the observed $\mathrm{CdS}$. The parameter $\beta$ in the equation above must be corrected with the instrumental width through the relation $\beta=\sqrt{\beta_{\exp }^{2}-\beta_{\text {inst }}^{2}}$, considering a Gaussian distribution for the diffracted peaks. The parameters $\beta_{\text {exp }}$ and $\beta_{\text {inst }}$ are the experimental and the instrumental linewidths, respectively. The value $\beta_{\text {inst }}$ was determined using a LaB6 (NIST SR660) powder standard pattern.

Figure 2 shows the grain size obtained by Scherrer's equation for [111] cubic direction as a function of the EDTA concentrations for all samples prepared by this new route. The open up-triangle, the filled square, and the open circle represent the group one, two and three solution, respectively. We observe that the grain size have nanometric dimension, ranging approximately from 8.0 to $26 \mathrm{~nm}$. The grain size increases when the group one go to group three, passing by group two, indicating a better quality for the film of group three.

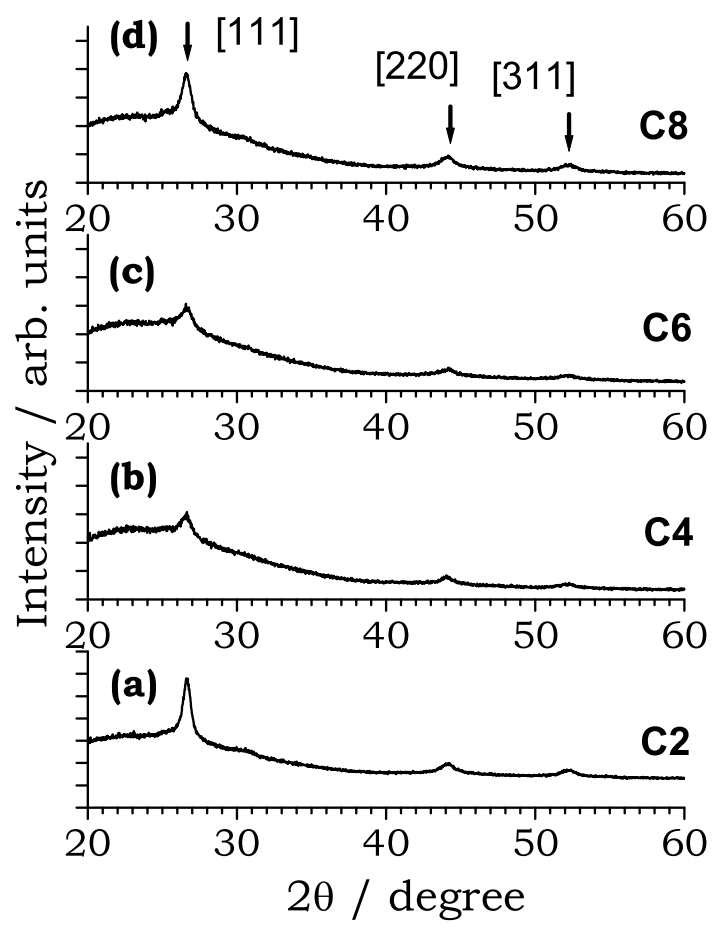

Figure 1. XRD of samples of the group two, with buffer solution and with different EDTA concentrations, as explained in text.

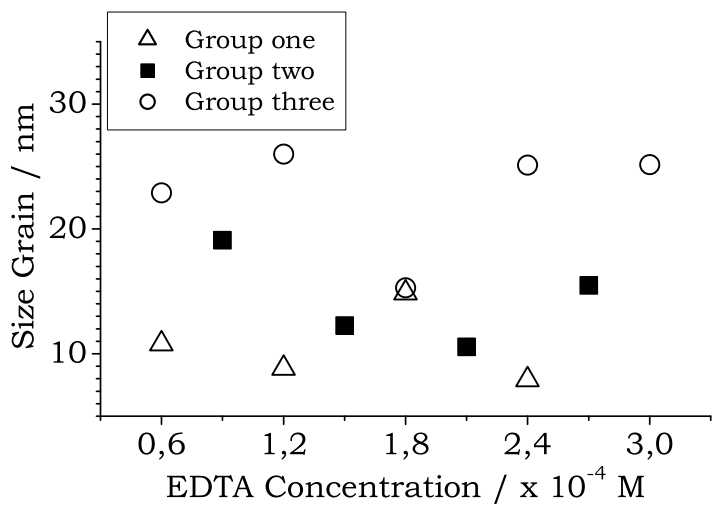

Figure 2. Grain size obtained using the Scherrer's equation, for all samples used in this work, as a function of EDTA concentration, as explained in text.

Figure 3 shows the XRD of the three films deposited at the same EDTA concentration of $\mathrm{C} 3=1.2 \times 10^{-4} \mathrm{M}$, in the Fig. 3(a) without buffer solution, in the Fig. 3(b) with addition of the buffer solution, and in the Fig. 3(c) the buffer solution plus TX100. It was observed that for all CdS film studied, their quality improves with solution-buffer and TX100. As the presence of buffer and TX100 keep the pH constant during the deposition, it was observed that the samples prepared by this way have improved the film quality. 


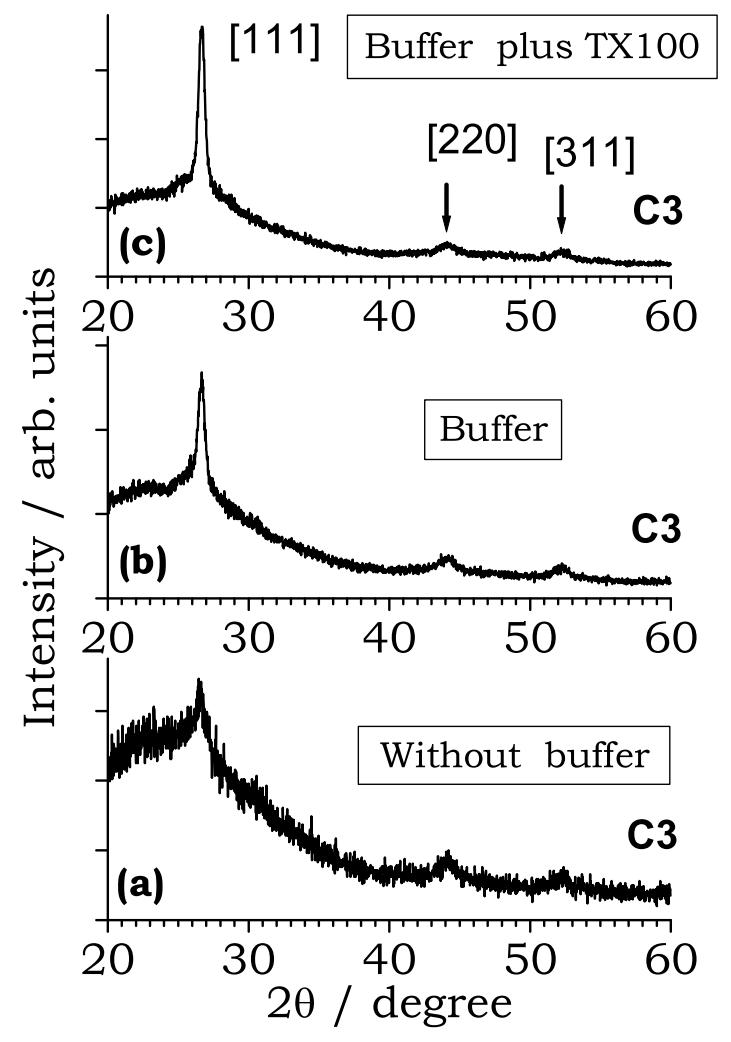

Figure 3. XRD of three films with the same C3 EDTA concentration. Without buffer in (a), with buffer in (b), and with buffer plus TX100 in (c).

\section{Conclusion}

The microstructural properties of $\mathrm{CdS}$ thin films deposited by CBD has been tested at first time, as a function of the EDTA ligand concentration. The CdS films present a cubic structure for all sample obtained. XRD was used to obtain the polycrystaline size grain using the Scherrer's equation, and their quality. Addition of solution-buffer and TX100 increase the size grain and consequently the quality of the films.

\section{Acknowledgement}

A. V. F. was supported by PIBIC/CNPq. The authors would like to thank to $\mathrm{MCT} / \mathrm{CNPq}$, for their partial support (Project number 471496/01-4).

\section{References}

[1] J. Britt, and C. Ferekides, Appl. Phys. Lett. 62, 2851 (1993).

[2] T. L. Chu, and S. S. Chu, Solid-State Electronics 38, 533 (1995).

[3] M. A. Green, Prog. Photovoltaics 9, 123 (2001).

[4] K. L. Chopra, S. Major, and D. K. Pandya, Thin Solid Films 102, 1 (1983).

[5] J. M. Dona and J. Herero, J. Electrochem. Soc. 144, 4091 (1997).

[6] A. E. Rakhshani, and A. S. Al-Azab, J. Phys.: Condens. Matter 12, 8745 (2000).

[7] M. A. Martínez, C. G, and J. Herrero, Appl. Sur. Sci. 136, 8 (1998).

[8] G. Contreras-Puente et al., Thin Solid Films 361, 378 (2000).

[9] S. J. Lade, and C. D. Lokhande, Mat. Chem. Phys. 49, 160 (1997).

[10] J. W. Park, K. R. Min, and E. Y. Jeung, B. Kor. Chem. Soc. 9, 408 (1988).

[11] T. I. Igumenova et al., J. Photochem. and Photobiology A: Chem. 94, 205 (1996).

[12] T. Sugimoto, G. E. Dirige, and A. Muramatsu, J. Colloid and Interface Sci. 182, 444 (1996).

[13] D. M. Zhou, S. Q. Wang, and H. M. Chen, J. Environ. Sci. Chi. 13, 153 (2001).

[14] R. Padmavathy et al., Mat. Lett. 53, 321 (2002).

[15] L. S. Birks, and H. Friedman, J. Appl. Phys. 16, 687 (1946). 